\title{
Modeling and Optimization of a Latent Heat Thermal Storage with Solar Absorption Chiller in Iran
}

\author{
Mohammad Mehdi Keshtkar*, Amin Sheibani \\ Department of Mechanical Engineering, Kerman Branch, Islamic Azad University, Kerman, Iran \\ Email address: \\ Mkeshtkar54@yahoo.com (M. M. Keshtkar) \\ ${ }^{*}$ Corresponding author
}

To cite this article:

Mohammad Mehdi Keshtkar, Amin Sheibani. Modeling and Optimization of a Latent Heat Thermal Storage with Solar Absorption Chiller in Iran. Science Journal of Energy Engineering. Vol. 4, No. 5, 2016, pp. 44-49. doi: 10.11648/j.sjee.20160405.12

Received: October 20, 2016; Accepted: November 3, 2016; Published: November 25, 2016

\begin{abstract}
The research in this paper focuses on the theoretical modeling and optimization of a solar absorption chiller system with a latent heat thermal storage using phase change material (PCM). At first for modeling the absorption chiller cycle, we use the thermodynamic principles. After that with considering the technical limitations we change this model to a standard mathematical planning model by using exergy analyses. At the second step, the mathematical model will be optimized by a genetic algorithm which is inspired by nature. The optimized parameters of cycle will be calculated accurately by doing this step. These parameters consists of the temperature of essential parts i.e. generator, evaporator, absorber, and condenser. Designing a storage system is necessary for resolving the important problem of sun systems which is not absorbing the light of sun at night. So that in the final step, a cylindrical system for storage of energy sun by using storage technique of thermal energy and PCM is designed. This system is analyzed by the enthalpy and Finite Volume Method which their parameters are, dimensions and type of the PCM.
\end{abstract}

Keywords: Exergy, Genetic Algorithm, Optimizing, Storage System, Finite Volume Method

\section{Introduction}

Nowadays, development and increase explosion of new and renewable energy systems is one of main needs of every society. Two reasons can be broached for this increasing of energies: 1) decreasing the amount and level of fossil fear's production. 2) Today's being discussed fossil fuels have more environmental results and new energies are excluded of this rule. One of these kinds of energy is solar energy of photovoltaics that currently have been used in small scales in different country. Main reason of run-used this energy on large industrial scales is high cost of structure against low efficiency. Researchers obliged to studying wide investigate of using this energy on large industrial scales in addition to small scales, because the freedom of input energy to solar systems.

Misra et al. $(2002,2003)$ have used first concept to optimize a LiBr-water absorption refrigeration system. They determined average cost per unit exergy of all internal flows. Kizilkan et al. (2007) used second concept to optimize a LiBr-water absorption refrigeration system thermoeconomically. Kim et al. (2011) used a micro genetic algorithm for optimizing the long-term performance of an active-indirect solar hot water plant in a flight kitchen at Changi international airport services. Kulkarni et al. (2007) proposed the "design space methodology" to design and optimization of an active-direct solar water heating system with one storage tank. A dynamic simulation tool specially devoted to the typical climates of South Italy for both winter heating and summer cooling load were presented by Calise et al. (2011) based on a rigorous mathematical algorithm. He also prepared a complete dynamic model of a solar-assisted heating and cooling system and used to develop a case study, including a detailed energy and economic analysis and optimization for different types of Italian school buildings. Prakash et al. (1985) applied a rectangular storage unit in water heater that contained a layer of PCM placed at the bottom. Sharma et al. (2003) developed latent heat storage unit for providing hot water in the evening and morning. Their used PCM was paraffin wax (m. p. $54^{\circ} \mathrm{C}$ ) in a box type solar collector. Ghoneim and Klein (1989) investigated theoretically phase change heat storage for hot air and hot water. Sodium sulfate decahydrate and paraffin were used as PCMs. Buddhi and Sahoo, 1997 used Sytric Acid as a 
PCM in a box type solar cooker. Tan et al. (2009) investigated heat transfer during constrained melting of PCM inside a spherical capsule. A smooth circular tube with effective specific heat technique was developed for evaluating the heat transfer performance of a PCM by Kandasamy et al. (2008). Also, a report was presented about the variation of thermal resistance in PCM and showed the effect of natural convection will not be as significant (Tay et al., 2012a). Moreover, they modeled shell and tube heat exchanger with PCM using CFD method that was developed by ANSYS code (Tay et al., 2012b). Solar energy is usable of two aspects: 1) photo voltaic systems produce electric energy. 2) Thermal system that operated in heating and cooling fields of building. By focus to this subject that there isn't any research in the field of cooling by absorption chiller along phase change material and optimization of these cycles, so this aims follow in the present work. Absorption system, operate heat of energies such as solar energy, geothermal energy and loss energy of industrial instruments for heating or cooling special environment like interior space of building. This system has high potential to save energy consumption and low-pollutant heat of environment.

By attention to the mention notes, aim of performing research and process of solving problem is as follow. In the first step, thermodynamic modeling and exeagy analyze done in single effect absorption chiller cycle with lithium-bromide and then principal parameters of cycle optimized by genetic algorithm. In the next step, type of collector, diameter and mass of phase change material are assigned. Finally, by focus on the time of using absorption chiller, temperature variation of PCM and HTF are being discussed on term of time.

\section{Thermodynamic Modeling and Exergy Analyze}

\subsection{Energy Analysis}

Schematic process of single effect absorption chiller cycle is shown in Fig. 1. Simple absorption system is composed from four main components. This system is composed from one evaporator, and absorber tower, on the low-pressure side of system and one generator and condenser on the high-pressure side of system. Working fluids are refrigerant (water) and absorbent $(\mathrm{LiBr})$. The path circulation of refrigerant is from condenser to evaporator, tower, generator and the condenser, respectively.

Some assumptions are considered from the point of view of system modeling:

1) System operates in the permanent conditions.

2) Output solution of generator and absorber are considered at saturation temperature.

3) Output fluid of condenser is considered at saturation temperature.

4) Output steam of evaporator is considered at saturation temperature.

5) Valves operate at constant enthalpy process.

The coefficient of performance of cooling system $\left(\mathrm{COP}_{\text {cool }}\right)$ can be defined for system as the ratio of heat extracted from evaporator to the total work of pump and input heat to generator and the coefficient of performance of heating system $\left(\mathrm{COP}_{\text {heat }}\right)$ can be defined for system as the ratio of total extracted heat of absorber and condenser to total work of pump and input heat to generator that are defined as follow:

$$
\begin{aligned}
& C O P_{\text {heat }}=\frac{Q_{a}+Q_{c}}{Q_{G}+W_{P}} \\
& C O P_{\text {cool }}=\frac{Q_{E}}{Q_{G}+W_{P}}
\end{aligned}
$$

Equilibrium equation of energy for total cycle of absorption as follow:

$$
Q_{e}+Q_{g}-Q_{a}-Q_{c}+W_{p}=0
$$

\subsection{Exergy Analysis}

According to exergy analysis, aim is obtaining destruction exergy for all components of system $\left(E_{k}\right)$ that $k$ index is referred to each of system component separately: evaporator, condenser, absorber tower, heat exchanger of solution and pump. Exergy equation balance of system can be defined as follow:

$$
\sum \dot{E}_{\text {in }}-\sum \dot{E}_{\text {out }}-\dot{Q}\left(1-\frac{T_{0}}{T}\right)-\dot{W}-\dot{E}_{D, k}=0
$$

By attention to above analysis, the effect of charging evaporator temperature, condenser, absorber and generator and also amount efficiency of heat exchange on COP and exergy efficiency of system are investigated (Fig. 2). After investigating the effect of each parameters, highest COP and exergy efficiency obtained by genetic algorithm. Then, operating point of system obtained from the point of view of COP and exergy efficiency.

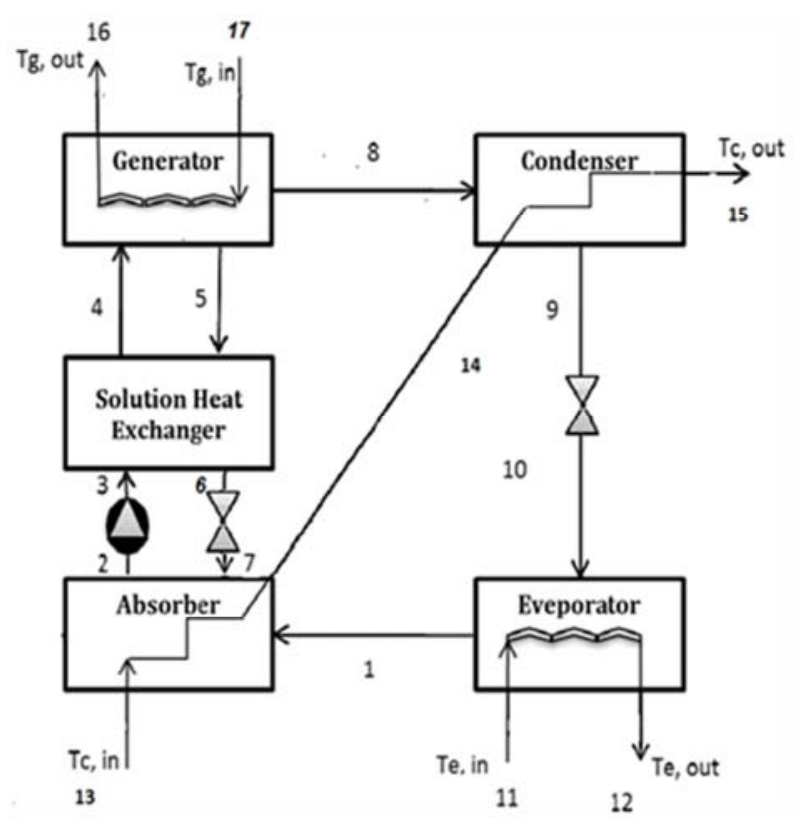

Fig. 1. Schematic of single effect absorption chiller. 

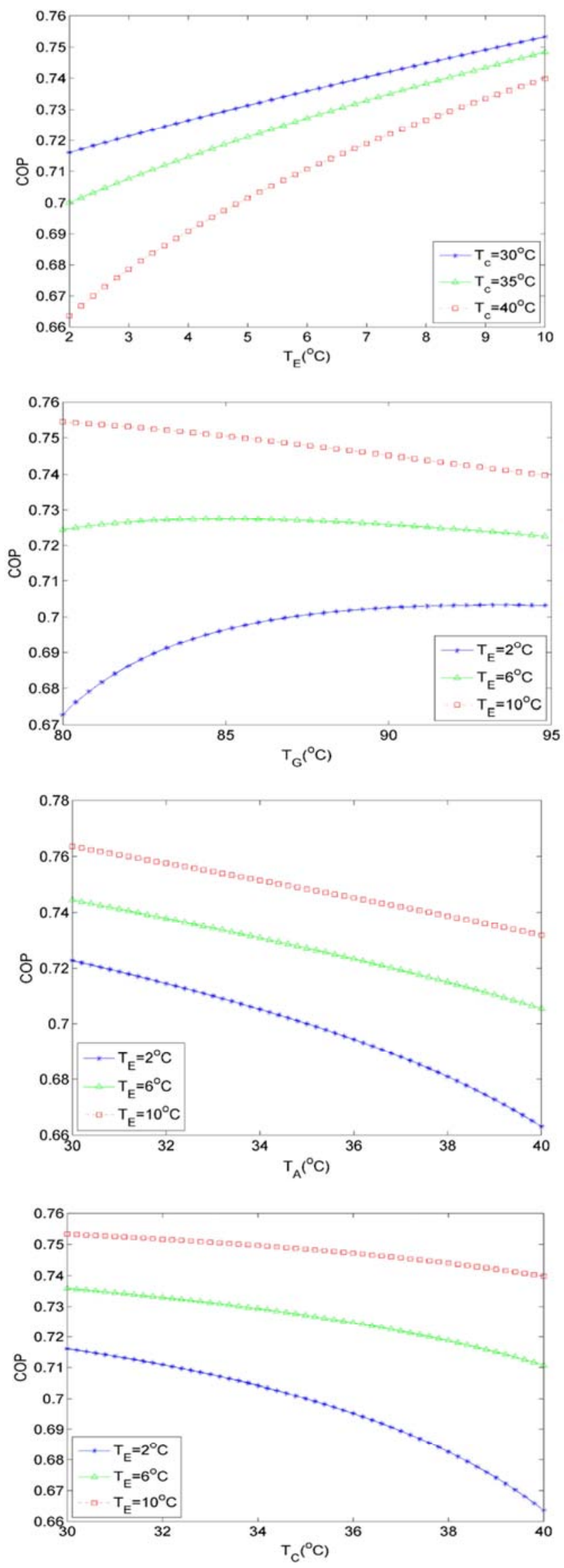
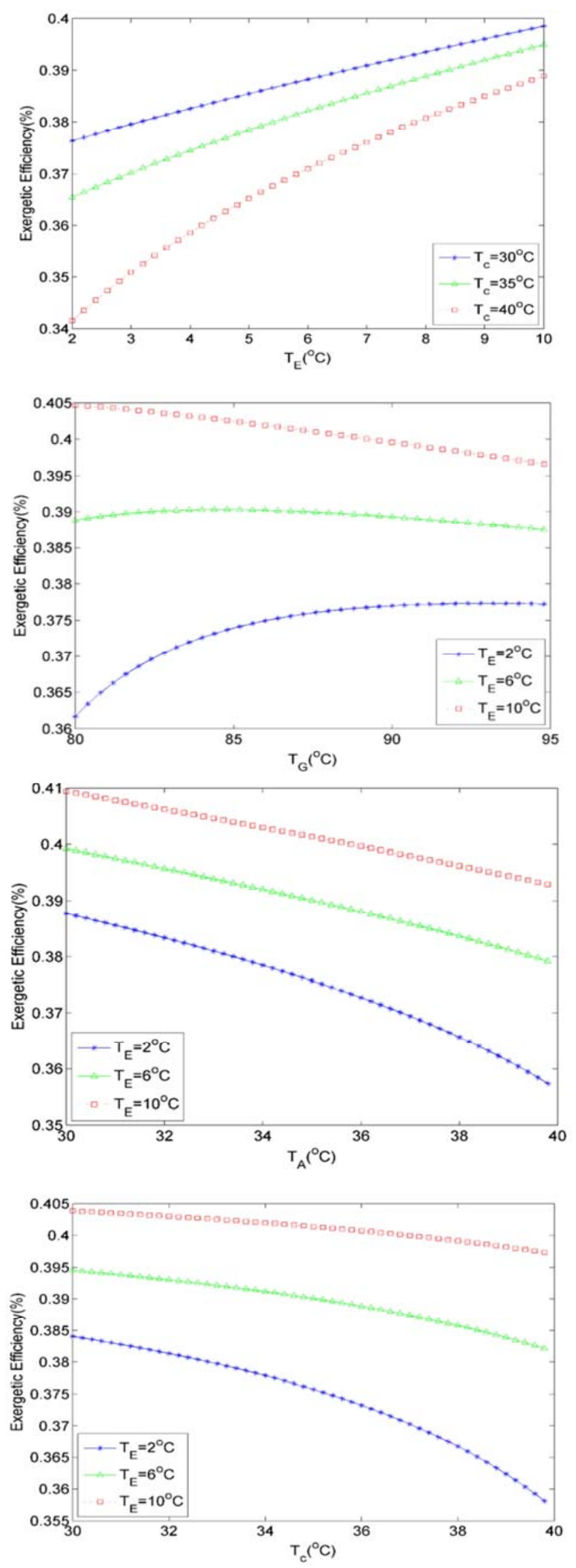

Fig. 2. Variation of different parameters versus evaporator, generator and absorber temperature. 


\subsection{Determination of Type of PCM, and Monthly Solar Radiation for Cooling System Along by Thermal Storage System}

For solar absorption chiller effective and economic daily thermal energy storage is unavoidable, because solar energy is unavailable during certain periods of the day and during the night. Among the various methods of energy storage, the latent heat thermal energy system using PCM is quite appealing, because of its high energy storage density and its ability to provide heat at a constant temperature.

Main system (chiller) is assumed to be used in hours from 9 AM to 9 PM. This system operates from 9 AM to 5 PM by solar energy that is provided by the collector, but Support Energy System (SES) supports it during period 5 PM to 9 PM that is during the time that collector does not receive sufficient solar radiation. The PCM to be used in the design of thermal storage systems should possess desirable thermophysical, kinetic and chemical properties and to have a melting temperature near to working temperature of main system. Working temperature of main system in this study to be provided by collector and storage system is $88^{\circ} \mathrm{C}$. So, the PCM used for this investigation is considered "Erythrol". The problem of phase change falls into the category of moving boundary problems. Solving this problem is done by enthalpy method. In this method the governing equation is divided into three states (liquid, mushy and solid) and each of state has specified governing equation. Up to now, after energy and exergy analyzing, here, by using thermal storage system with phase change material (PCM), need heat of generator provided by solar collector.

Location of Iran on north of 25-45 degrees latitude, is caused average solar energy about $19.23 \mathrm{MJ} / \mathrm{m}^{2}\left(5.3 \mathrm{kWh} / \mathrm{m}^{2}\right.$. day). In this country amount of sunny hours is more than 2800 hours in year and according to government's policy to develop produce of energy by new technique indicated the high potential of Iran to operating solar energy in different purpose. In present study, design of solar system is considered for $700 \mathrm{~m}^{2}$ building area and positive space of ventilation is $600 \mathrm{~m}^{2}$ in Tehran. Operation time of system is 16 hours, 10 hours relate to day and 6 hour relief to night. The period of operation time of system is to consider for 5 month of year between 15 Ordibehsht (May) to $15 \mathrm{Mehr}$ (October). So, we refer to NASA data that is one of most valuable information resource to calculate solar radiation intensity and absorption.

According to this resource in July (Tir-Mordad) at Tehran, the average of solar radiation intensity is equal to, $7.5 \mathrm{kWh} / \mathrm{m}^{2}$ day, on horizontal surface. By assumption of about 9 hour radiation for this month of summer, so the amount of solar radiation monthly on horizontal surface is equal to $G=834 \mathrm{w} / \mathrm{m}^{2}$. This power of solar-radiation of monthly is used to calculate of input thermal to collector.

By attention to gathering information of articles, we install collector on south side with angle of 36 degree which is about equal to Tehran's latitude.

\subsection{Selecting Collector Which Is Connected to Storage System}

Main section and the heart of solar system is solar collector of system which transfers thermal energy to the working fluid inside the collector by absorbing solar radiation energy and exchange of it to heat.

It is noticeable that, the most suitable collector for solar absorption chiller (single-effect) is vacuum pipe collector type.

Need heat of generator is obtained by specified parameters in previous section by attention to synchronic optimization of COP and exergy efficiency.

By focus to below equation one can be calculate transferred heat by collector:

$$
q_{\text {collector }}=F_{R}(\tau \alpha)_{\text {ave }} \cdot G-F_{R} U_{L} \Delta T
$$

For vacuum pipe collector value of $\mathrm{F}_{\mathrm{R}} \mathrm{U}_{\mathrm{L}}$, is about 0.7 and $F_{R}(\tau \alpha)_{\text {ave }}$ is about 0.689 .

Mass flow rate of nano fluid inside the collector is calculated by using optimum amount of $\mathrm{Q}_{\mathrm{gen}}$ and so we can assign need surface of solar collector.

The collector efficiency, is given by below equation:

$$
\eta=\frac{q_{\text {collector }}}{\overline{G_{t}}}
$$

Finally, by attention to the collector area and absorbent area of each vacuum pipe which is equal to $0.0804 \mathrm{~m}^{2}$, so, the number of vacuum pipe is calculated.

By focus to this note, that each 22 pipe compose one collector, so the number of need collector is calculated.

In this section, system calculations have been done by attention to previous condition along thermal storage system in two state of day and night.

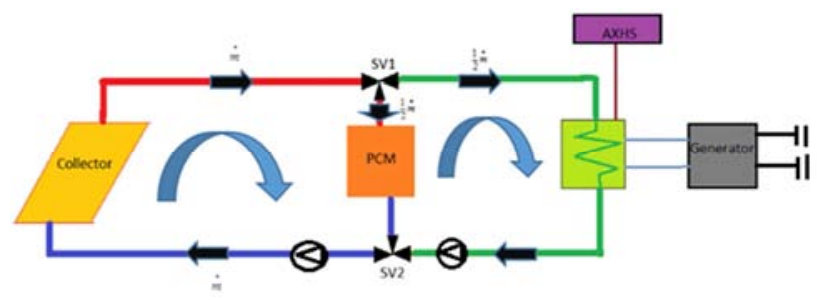

(a)

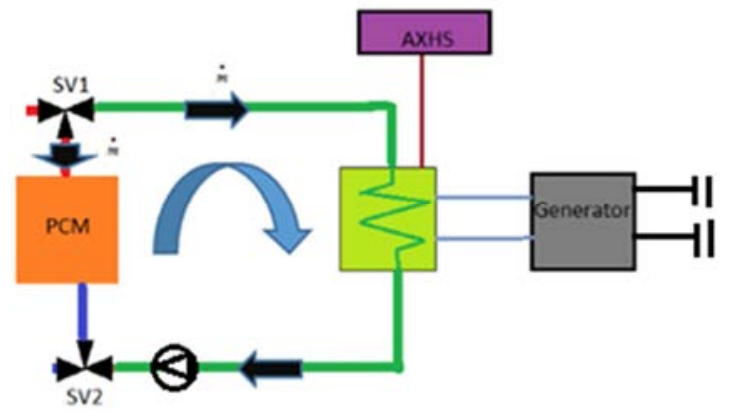

(b)

Fig. 3. Schematic of collector and PCM at (a) day (b) night. 
Through the day, 40 percent of need thermal of generator and thermal energy to melting PCM is provided by solar energy and $60 \%$ remain of this thermal energy is provided by auxiliary heating system (AXHS) (Fig. 3a). Absorbed solar energy of collector $\left(\mathrm{q}_{\text {collector }}\right)$ is used to supply need thermal energy of generator and need thermal energy of melting PCM at during of the day. By assumption of 50 percent of mass flow rate of nano fluid is for the supply of 40 percent of need thermal energy of generator, so, amount of mass flow rate will be equal to $2.7 \mathrm{~kg} / \mathrm{s}$. 50 percent of remain mass flow rate of HTF will be arrived into the thermal storage system. HTF in thermal storage section provides need heat for melting of solid PCM. Solid PCM is liquefied and then prepared to giveback heat and supply need thermal of generator during the night.

During the night, elective valves $\mathrm{SV}_{2}, \mathrm{SV}_{1}$ are closed (Fig. 3b). At this case, input temperature of HTF is equal to $30^{\circ} \mathrm{C}$, that this temperature increases by $\mathrm{PCM}$ until $40^{\circ} \mathrm{C}$ and remain thermal energy is provided by auxiliary heating system. Now, by attention to this subject that the mass flow rate of HTF provides need thermal energy for melting of PCM, so, accumulated thermal energy inside the PCM released and the temperature of $\mathrm{HTF}$ increases from $30^{\circ} \mathrm{C}$ to $40^{\circ} \mathrm{C}$ during the night. We can assign time of discharging of PCM by considering of charging time and mass flow rate of HTF during the night. Accumulated energy inside the PCM in the period of charging time is equal to removal heat of PCM in the period of discharging time and absorbing heat by Nano fluid. According to Fig. 4 time of attaining HTF to $40^{\circ} \mathrm{C}$ is equal to 100 minutes after operating thermal discharge. It should be mentioned that in the time of discharging, accumulated thermal energy inside the PCM transmits to nano fluid material. According to this subject, need thermal of HTF in this system will be $40^{\circ} \mathrm{C}$ until about 5 hours. Need thermal energy to bring $\mathrm{HTF}$ temperature from $40^{\circ} \mathrm{C}$ to $88^{\circ} \mathrm{C}$ which is the temperature of operating single-effect absorption cooling system is provided by auxiliary heating system.

By attention to optimization of cooling cycle in previous section, amount need thermal of generator in optimum state calculated. According to the optimization results by genetic algorithm, maximum of $\mathrm{COP}$ will be equal to 0.778 , temperature of evaporator, condenser, generator and absorber in COP mode is $10,30,80$ and $30^{\circ} \mathrm{C}$, respectively. Maximum exergy efficiency is 0.423 and temperature of evaporator, condenser, generator and absorber in exergy efficiency mode is $10,30,80,30^{\circ} \mathrm{C}$, respectively.
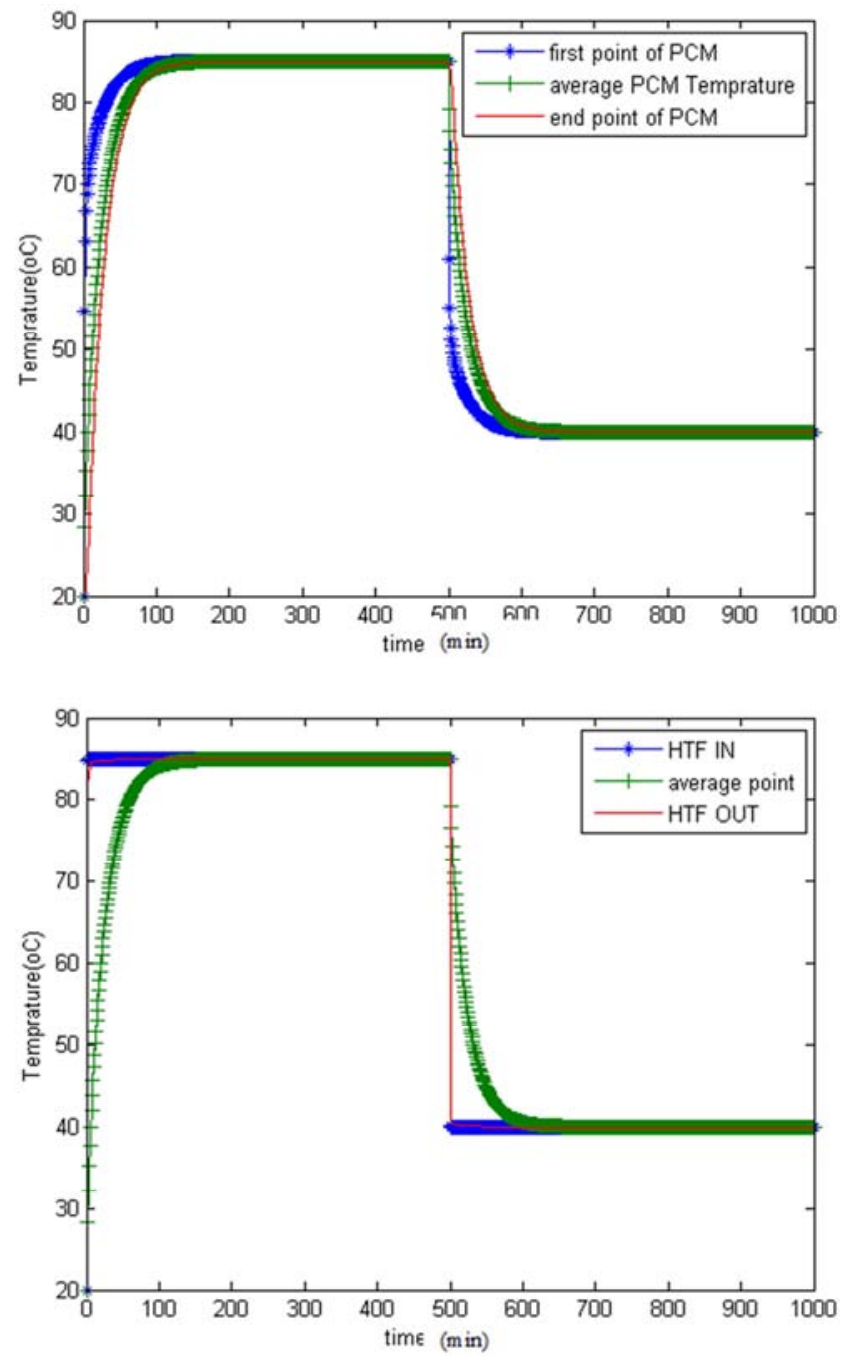

Fig. 4. Variation of PCM and HTF temperature versus time. 
By synchronic optimization of exergy efficiency and COP, these parameters will be obtained 0.417 and 0.778 , respectively. Temperature of evaporator, condenser, generator and absorber in multi object optimization are 8.4, 30.2, 80.2 and $30.33^{\circ} \mathrm{C}$, respectively. Table 1 shows range of COP difference according to various temperature range for components at $\mathrm{T}_{\mathrm{E}}=10^{\circ} \mathrm{C}$

Table 1. Variation of COP at different temperature range.

\begin{tabular}{lll}
\hline Parameter & Temp Range & COP Diff \\
\hline Absorber $\left({ }^{\circ} \mathrm{C}\right)$ & $30<\mathrm{T}_{2}<40$ & 0.032 \\
Generator $\left({ }^{\circ} \mathrm{C}\right)$ & $80<\mathrm{T}_{5}<95$ & 0.015 \\
Condenser $\left({ }^{\circ} \mathrm{C}\right)$ & $30<\mathrm{T}_{9}<40$ & 0.014 \\
\hline
\end{tabular}

Table 2 shows range of exergy efficiency difference according to different temperatures for components at $\mathrm{T}_{\mathrm{E}}=10^{\circ} \mathrm{C}$

Table 2. Variation of exergetic efficiency at different temperature range.

\begin{tabular}{lll}
\hline Parameter & Temp Range & exergy efficiency \\
\hline Absorber $\left({ }^{\circ} \mathrm{C}\right)$ & $30<\mathrm{T}_{2}<40$ & 0.016 \\
Generator $\left({ }^{\circ} \mathrm{C}\right)$ & $80<\mathrm{T}_{5}<95$ & 0.008 \\
Condenser $\left({ }^{\circ} \mathrm{C}\right)$ & $30<\mathrm{T}_{9}<40$ & 0.01 \\
\hline
\end{tabular}

\section{Conclusions}

Finally, by attention to modeling and optimization of absorption cooling system of liBr-water, concluded that:

1) By increasing evaporator temperature, COP and exergy efficiency will be increase.

2) By increasing condenser temperature $\mathrm{COP}$ and exergy efficiency will be decrease.

3) By increasing generator temperature, COP and exergy efficiency will be increase and then decrease.

4) By increasing absorber temperature, COP and exergy efficiency will be decrease.

According to positive area of $600 \mathrm{~m}^{2}$, cooling capacity is $84.48 \mathrm{~kW}$ and generator power is $118.45 \mathrm{~kW}$. So $47.38 \mathrm{~kW}$ of this thermal is provided by solar collector and $71.07 \mathrm{~kW}$ of it, is provided by AXHS. By synchronic optimization of exergy efficiency and COP, these parameters will be obtained 0.417 and 0.778 , respectively. Temperature of evaporator, condenser, generator and absorber in multi object optimization are $8.4,30.2,80.2$ and $30.33^{\circ} \mathrm{C}$, respectively. Material of HTF provides need thermal energy to melting $62 \mathrm{~kg}$ of PCM (Erythrol) which is inside 50 storage pipes and melting temperature of it is equal to $135^{\circ} \mathrm{C}$. Total transfer thermal by HTF is equal to $132.51 \mathrm{~kW}$. By attention to this subject that output power to collector area is equal to $541.35 \mathrm{~W} / \mathrm{m}^{2}$, so collector need area will be equal to $242.76 \mathrm{~m}^{2}$ and then we will need 3014 discharge pipes. Each 22 pipe constitute one separate collector and it is clearly that we will need 138 collectors. Also, amount efficiency of it, is equal to $64.9 \%$. By focus to above chart, it is clearly that. Time of charging is assumed 10 hours and time of attaining $\mathrm{HTF}$ to $40^{\circ} \mathrm{C}$ is equal to 100 minutes. According to this subject, need thermal of HTF in this system will be $40^{\circ} \mathrm{C}$ until about 5 hours.

\section{Nomenclature}

\author{
A: Absorber \\ $C$ : Condenser \\ $E$ : Evaporator \\ $G$ : Generator \\ $P$ : Solution Pump
}

\section{Acknowledgment}

This work supported by Research Program supported by the Department of Mechanical Engineering Azad university of kerman, Iran.

\section{References}

[1] Misra R. D, Sahoo P. K, Gupta A, 2005, Thermodynamic optimization of a single effect vapor absorption refrigeration system, Journal of Energy Resources Technology, 26: 158-169.

[2] Kizilkan G. A, Kalogirou S. A, Tassou S. A, Worbel L. C, 2007, Design and construction of a LiBr-water absorption machine, Energy Conversion and Management, 44: 2483-2508.

[3] Kim SO, 2011, Performance of a natural circulation solar air heating system with phase change material energy storage, Renewable Energy: 27: 69-86.

[4] Kulkarni. A. S., Mehr, A., 2007, Cooking during off sunshine hours using PCMs as storage media, Fuel Energy Abstr: 36 (5): 348 .

[5] Calise D, Sharma SD, Sharma A, 2011, Thermal performance evaluation of a latent heat storage unit for late evening cooking in a solar cooker having three reflectors, Energy Convers Manage: 44: 809-17.

[6] Prakash J, Morris DR, Steward FR, 1985, Exergy analysis of thermal, chemical and metallurgical processes, New York: Hemisphere Publishing Corporation.

[7] Sharma L, 2003, Design and Analysis of a solar assisted absorption cooling system integrated with latent heat storage, Delft University of technology.

[8] Ghoneim J. A, Klein W. A, 1989, Performance of a solar air heating system with phase change material energy storage, Renewable Energy, 43-323.

[9] Buddhi D, Sahoo, S. A, 1997, An introduction to Genetic algorithms for scientists and engineers. World Scientific.

[10] Ten J. H,, Morris DR, 2009, Adoption in natural and artificial systems, Ann Arbor: The University of Michigan Press.

[11] Kandasamy, S. C, A. Arora, 2009, Energy and exergy analysis of single effect and series low double effect water-lithium bromide absorption refrigeration systems, International Journal of Refrigeration: 32: 1247-1258.

[12] Tay, A. S., Mehr, S. M, Mahmoudi, S., 2012, Simulation study of the combination of absorption refrigeration and ejectorexpansion systems, Renewable Energy: 60:370-381.

[13] Tay, A. S., Brinkwarth BJ, 2012, The storage of low grade thermal energy using phase change materials, Appl Energy: 2: 205-16. 